OPEN ACCESS

Edited by:

John T. Fisher,

Queen's University, Canada

Reviewed by:

Joseph Arnold Fisher,

University Health Network (UHN),

Canada

Hari H. Subramanian,

Boston Scientific, United States

${ }^{*}$ Correspondence: Valérie Attal

valerie.attali@aphp.fr

Specialty section:

This article was submitted to Respiratory Physiology,

a section of the journal

Frontiers in Physiology

Received: 23 November 2018

Accepted: 01 April 2019

Published: 24 April 2019

Citation:

Attali V, Clavel L, Rouch P, Rivals I, Rémy-Néris S, Skalli W, Sandoz B and

Similowski T (2019) Compensation of Respiratory-Related Postural Perturbation Is Achieved by Maintenance of Head-to-Pelvis Alignment in Healthy Humans. Front. Physiol. 10:441. doi: 10.3389/fphys.2019.00441

\section{Compensation of Respiratory-Related Postural Perturbation Is Achieved by Maintenance of Head-to-Pelvis Alignment in Healthy Humans}

\author{
Valérie Attali ${ }^{1,2,3 *}$, Louis Clavel',3, Philippe Rouch ${ }^{3}$, Isabelle Rivals ${ }^{1,4}$, \\ Ségolène Rémy-Néris ${ }^{1}$, Wafa Skalli ${ }^{3}$, Baptiste Sandoz ${ }^{3}$ and Thomas Similowski1,5 \\ 1 INSERM, UMRS1158 Neurophysiologie Respiratoire Expérimentale et Clinique, Sorbonne Université, Paris, France, \\ 2 Service des Pathologies du Sommeil (Département "R3S"), Hôpitaux Universitaires Pitié Salpêtrière - Charles Foix, \\ Assistance Publique Hôpitaux de Paris (APHP), Paris, France, ${ }^{3}$ Arts et Metiers ParisTech, Institut de Biomécanique Humaine \\ Georges Charpak (IBHGC), Paris, France, ${ }^{4}$ Equipe de Statistique Appliquée, ESPCI Paris, PSL Research University, Paris, \\ France, ${ }^{5}$ Médecine Intensive et Réanimation (Département "R3S"), Hôpitaux Universitaires Pitié Salpêtrière - Charles Foix, \\ APHP, Paris, France
}

The maintenance of upright balance in healthy humans requires the preservation of a horizontal gaze, best achieved through dynamical adjustments of spinal curvatures and a pelvic tilt that keeps the head-to-pelvis alignment close to vertical. It is currently unknown whether the spinal and pelvic compensations of respiratory-related postural perturbations are associated with preservation of the head-to-pelvis vertical alignment. We tested this hypothesis by comparing postural alignment variables at extreme lung volume (total lung capacity, TLC; residual volume, RV) with their reference value at functional residual capacity (FRC). Forty-eight healthy subjects [22 women; median age of 34 (26; 48) years] were studied using low dose biplanar X-rays (BPXR; EOS ${ }^{\circledR}$ system). Personalized three-dimensional models of the spine and pelvis were reconstructed at the three lung volumes. Extreme lung volumes were associated with changes of thoracic curvature bringing it outside the normal range. Maximal inspiration reduced thoracic kyphosis $\left[\mathrm{T} 1-\mathrm{T} 12\right.$ angle $=47^{\circ}(37 ; 56),-4^{\circ}$ variation $\left.(-9 ; 1), p=0.0007\right]$ while maximal expiration induced hyperkyphosis $\left[\mathrm{T} 1-\mathrm{T} 12\right.$ angle $=63^{\circ}(55 ; 68) ;+10^{\circ}$ variation (5; 12), $p=9 \times 10^{-12}$ ]. Statistically significant (all $p<0.01$ ) cervical and pelvic compensatory changes occurred $\left[\mathrm{C} 3-\mathrm{C} 7\right.$ angle: $+4^{\circ}(-2 ; 11)$ and pelvic tilt $+1^{\circ}$ $(0 ; 3)$ during maximal inspiration; C3-C7 angle: $-7^{\circ}(-18 ;-1)$ and pelvic tilt $+5^{\circ}(1 ; 8)$ during maximal expiration], resulting in preserved head-to-pelvis alignment (no change in the angle between the vertical plane and the line connecting the odontoid process and the midpoint of the line connecting the center of the two femoral heads ODHA). Lung volume related postural perturbations were more marked as a function of age, but age did not affect the head-to-pelvis alignment. These findings should help understand balance alterations in patients with chronic respiratory diseases that modify lung volume and rib cage geometry.

Keywords: biplanar X-ray, personalized 3D models of the spine, lung volume, postural alignment, cervical and pelvic compensatory mechanisms 


\section{INTRODUCTION}

The maintenance of upright balance in healthy humans largely depends on the preservation of an horizontal gaze (Hasegawa et al., 2017). In this respect, achieving optimal balance with minimal energy expenditure implies keeping the head-to-pelvis alignment near vertical (Vital and Senegas, 1986; Dubousset, 1994; Amabile et al., 2018). Spinal curvatures and pelvic tilt are continuously adjusted to this effect, on the basis of information transmitted to the central nervous system via visual and proprioceptive afferents (Perennou et al., 2008; Amabile et al., 2016).

Although seldomly integrated into models describing human balance and spinal stability (Granata and Wilson, 2001), the rib cage imposes important postural adjustment constraints. Costovertebral joints limit flexion (especially lateral) and rotation of the thoracic spine (Liebsch et al., 2017) and their mechanical properties modulate the force exerted on the upper lumbar spine during trunk flexion (Ignasiak et al., 2016). In addition, breathing involves rotation of the costovertebral joints that modifies spinal curvature and, consequently, spinal postural alignment (Dally, 1908). It ensures that breathing induces a cyclic postural perturbation. This is reflected by respiratory-induced oscillations of the center of pressure, defined as the projection to the ground of the barycenter of vertical reaction forces, distributed over the entire surface of foot-ground contact. These oscillations disappear during breath-holding (Caron et al., 2004). They increase when ventilation increases (David et al., 2012).

The postural perturbations related to breathing in healthy subjects are centrally integrated and cyclically compensated by variations of spinal muscular rigidity (phasic contractions of paravertebral muscles), ensuring the maintenance of balance (Kantor et al., 2001; Hamaoui et al., 2010). Pelvic adaptations, consisting of phasic contractions of pelvic floor muscles synchronous with diaphragmatic contractions (Hodges et al., 2007; Talasz et al., 2011) and "respiratory" changes of lumbopelvic and hip angles (Grimstone and Hodges, 2003), are also involved in cyclic compensation of breathing-related postural perturbations. Whether or not the spinal and pelvic compensations of respiratory-related postural perturbations are associated with preservation of the head-to-pelvis vertical alignment (as a general balance maintenance mechanism) is currently unknown. The present study was designed to test the hypothesis that this is indeed the case, namely that head-topelvis vertical alignment is not affected by lung volume. To this purpose, we used the $\mathrm{EOS}^{\circledR}$ imaging device, a low-dose irradiation biplanar X-ray system (BPXR) (Dubousset et al., 2008) validated for the three-dimensional description of the normal and pathological weight bearing spine (Ilharreborde et al., 2013). With this device, we describe postural alignment and its adjustments as a function of lung volume in upright healthy volunteers. To maximize the effects of lung volume on spinal geometry (and therefore to test our hypothesis under the most extreme compensatory conditions), we performed our measurements over the full range of vital capacity (VC), namely at residual volume (RV, end of a maximal expiration) and total lung capacity (TLC, end of a maximal inspiration), using functional residual capacity (FRC, end-expiratory relaxation volume) as our reference point.

\section{MATERIALS AND METHODS}

\section{Subjects}

Fifty healthy subjects [22 women, 28 men, $34(26 ; 48)$ years, Body Mass Index $\left.24(21 ; 26) \mathrm{kg} / \mathrm{m}^{2}\right]$ with no signs of postural dysfunction on clinical examination and normal pulmonary auscultation and pulmonary functional tests, were included. This study was approved by the Comité de Protection des Personnes Ile-de-France VI (Ethics Committee) on February 18,2015 and is registered in the ISRCTN registry under number ISRCTN56129394. All patients provided their written informed consent.

\section{Reference Spirometric Values}

Prior to the biplanar X-ray acquisitions (BPXR), pulmonary function tests were performed according to recommended standards (Wanger et al., 2005), using a spirometer to measure vital capacity (VC) and the helium dilution technique to measure FRC and calculate residual volume (RV, equal to FRC minus expiratory reserve volume -ERV-) and total lung capacity (TLC, equal to FRC plus inspiratory capacity -IC-) (Brown et al., 1998). The values of IC and ERV measured during pulmonary function testing are noted $\mathrm{IC}_{\mathrm{pft}}$ and $\mathrm{ERV}_{\mathrm{pft}}$, respectively.

\section{Lung Volumes During BPXR Acquisitions}

Biplanar X-Rays (BPXR, see method next paragraph and Figure 1) were acquired during voluntary breath holding at relaxation volume (Vrelax, representing FRC), maximum inspiration (Vmax, intended as representative of TLC), maximum expiration (Vmin, intended as representative of $\mathrm{RV})$. Changes in lung volumes between BPXR acquisitions were measured using a spirometer (low resistance pneumotachograph, M.E.C. PFT Systems Pocket-Spiro, Medical Electronics Construction, Brussels, Belgium), with the subjects wearing a nose-clip and breathing through a mouthpiece. The Vmax acquisition was performed after a maximal inspiration initiated from the end of a tidal expiration under steady-state conditions (stable tidal volume over several breathing cycles). During the acquisition (10 to $20 \mathrm{~s}$ depending on height), the subjects were verbally encouraged to maintain breath-hold while relaxing. After completion of the acquisition, the subject was asked to expire completely, then breathe quietly for several cycles, before disconnecting the spirometer. The Vmin acquisition was performed after a maximal expiration initiated from the end of a tidal expiration under steady-state conditions. The same procedure as for the Vmax acquisition was followed. IC and ERV were measured during the Vmax and Vmin acquisitions $\left(\mathrm{IC}_{\mathrm{bpxr}}\right.$ and $\mathrm{ERV}_{\mathrm{bpxr}}$, respectively) (see Figure 1).

\section{Biplanar Controlled Lung Volume Xrays of the Skeleton}

The EOS $^{\circledR}$ system (EOS ${ }^{\circledR}$ Imaging, France) is a low-dose biplanar $\mathrm{x}$-ray system using sources placed at an angle of $90^{\circ}$, allowing 

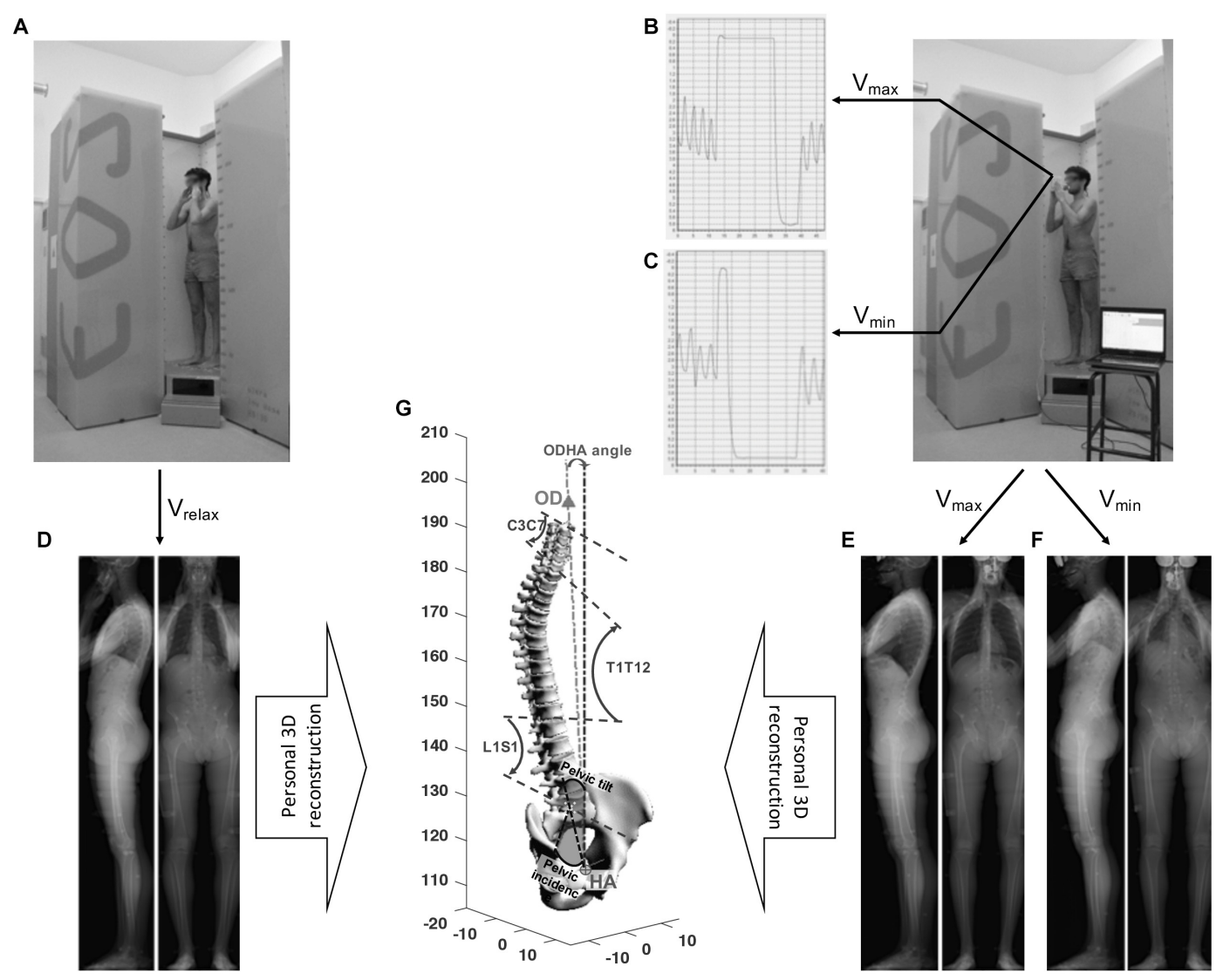

FIGURE 1 | Experimental procedures. Low-dose, biplanar X-ray (BPXR) acquisitions at Vrelax in the standardized free-standing position (A) and using spirometry-controlled lung volume at $V \max (\mathbf{B})$ and $V \min (\mathbf{C})$. Subject is fitted with a nose-clip and breaths through a mouthpiece connected to the spirometer. Spirometric curves are presented for Vmax (B) and Vmin (C). BPXR acquisitions are done during breath holding. From frontal and sagittal radiological images at Vrelax (D), Vmax (E), and Vmin (F), three 3D model specific are reconstructed (one model for each volume condition, but only one is represented in this figure) (G) including the odontoid process of C2 (OD), spine from C3 to S1 and pelvis. Then BPXR parameters are measured: C3-C7, T1-T12 and L1-S1 curvatures, pelvic variables, the angle between the vertical plane and the line through $\mathrm{OD}$ and the midpoint of the line connecting the center of the two femoral heads (HA) (ODHA).

simultaneous acquisition of frontal and sagittal radiological views of the whole skeleton (Dubousset et al., 2008). The first acquisition was performed at Vrelax, according to the procedure described by Amabile et al. (2016). Subjects were placed in the standardized free-standing position, with their hands placed on the cheek bone on each side of the face and breathed quietly during the acquisition. Then, BPXR acquisitions at Vmax and Vmin were then performed as described above. During these acquisitions, the position of the hands was slightly modified, as they were placed slightly more anteriorly in order to hold the spirometer. Of note, simulated acquisitions at Vmax and Vmin were performed before the actual acquisitions, to accustom the subject to the imaging procedure. The experimental plan is shown in Figure 1.

\section{BPXR Image Processing and Variables Recorded}

A 3D model specific to each subject was constructed from frontal and sagittal radiological images. This model included the superior tip of the odontoid process of C2 (OD), the vertebrae from C3 to
S1 and the pelvis. This model (see Figure 1) was produced by using validated reconstruction techniques (Mitton et al., 2006; Humbert et al., 2009). The following variables were calculated from this $3 \mathrm{D}$ reconstruction: (1) cervical (C3-C7), thoracic (T1T12) (T4-T12) and lumbar (L1-S1) spinal curvatures, expressed in degrees; (2) pelvic variables (pelvic incidence, sacral slope and pelvic tilt); (3) the angle between the vertical plane and the line through OD and the midpoint of the line connecting the center of the two femoral heads (ODHA); (4) the anteroposterior distance between the vertical projection of $\mathrm{C} 7$ and the superolateral border of S1 (Sagittal Vertical Axis: SVA) (Amabile et al., 2016). OHDA characterizes the head-to-pelvis alignment (the smaller this value is, the closer the head-to-pelvis is to the vertical).

\section{Simulated Effects of Lung Volume Changes on Verticality in the Absence of Pelvic and Cervical Compensation}

The following simulation was devised to illustrate what the impact of lung volume changes on posture would be in the absence of any pelvic and cervical spinal compensation: 
we reconstructed the whole pelvis-spine ensemble at Vmin and Vmax using the values of $\mathrm{C} 3-\mathrm{C} 7$ curvature and pelvic tilt by measured at Vrelax instead of their actual Vmin and Vmax values. This yielded "uncompensated values" of ODHA in the sagittal plane (ODHA sagittalSimu $)$ and of SVA $\left(\mathrm{SVA}_{\text {simu }}\right)$. We then confronted ODHA $\mathrm{O}_{\text {sagittalSimu }}$ and $S_{V A}$ simu at Vmin and Vmax to the range of values obtained for respectively, ODHA and SVA at Vmin and Vmax (considered as reference values in this group of subjects without any postural dysfunction), to estimate what would become of postural stability in the absence of cervical and pelvic compensation.

\section{Statistical Analysis}

The distribution of most variables were non-normal, and all results are expressed as a median and interquartile range $(\mathrm{Q} 1$; Q3). To evaluate how Vmax and Vmin were representative of

TABLE 1 | Baseline characteristics, pulmonary function tests and BPXR variables at Vrelax.

\begin{tabular}{lc}
\hline & Baseline characteristics $\boldsymbol{N}=\mathbf{4 8}$ \\
\hline Gender M/F & $26 / 22$ \\
Age (years) & $34[26 ; 48]$ \\
Height $(\mathrm{m})$ & $1.72[1.65 ; 1.76]$ \\
Weight $(\mathrm{kg})$ & $71[62 ; 78]$ \\
BMl $\left(\mathrm{kg} / \mathrm{m}^{2}\right)$ & $23.6[21.8 ; 25.9]$ \\
\hline
\end{tabular}

\begin{tabular}{|c|c|c|}
\hline \multicolumn{3}{|c|}{ Pulmonary function tests reference values } \\
\hline & $\mathbf{L}$ & $\%$ predicted \\
\hline $\mathrm{VC}_{\mathrm{pft}}$ & $4.9[4.0 ; 5.8]$ & $113[104 ; 126]$ \\
\hline $\mathrm{I}_{\mathrm{pft}}$ & $3.3[2.7 ; 4.0]$ & $119[106 ; 128]$ \\
\hline $\mathrm{ERV}_{\text {pft }}$ & $1.6[1.3 ; 1.9]$ & $112[99 ; 130]$ \\
\hline $\mathrm{FRC}_{\mathrm{pft}}$ & $3.3[2.8 ; 3.7]$ & $103[96 ; 111]$ \\
\hline$R V_{\text {pft }}$ & $1.7[1.3 ; 1.9]$ & $87[77 ; 102]$ \\
\hline $\mathrm{TLC}_{\mathrm{pft}}$ & $6.5[5.6 ; 7.8]$ & $106[100 ; 117]$ \\
\hline
\end{tabular}

BPXR parameters at Vrelax

\begin{tabular}{lc}
\hline Pelvic incidence $\left({ }^{\circ}\right)$ & $51[43 ; 60]$ \\
Pelvic tilt $\left(^{\circ}\right)$ & $12[9 ; 16]$ \\
Sacral slope $\left({ }^{\circ}\right)$ & $-40[-49 ;-34]$ \\
$\mathrm{ODHA}_{3 D}\left({ }^{\circ}\right)$ & $3[2 ; 4]$ \\
$\mathrm{ODHA}_{\text {sagittal }}\left(^{\circ}\right)$ & $-3[-4 ; 1]$ \\
$\mathrm{ODHA}$ frontal & $\left({ }^{\circ}\right)$ \\
$\mathrm{SVA}(\mathrm{mm})$ & $0[-1 ; 0]$ \\
$\mathrm{C} 3-\mathrm{C} 7\left(^{\circ}\right)$ & $-7[-23 ; 3]$ \\
$\mathrm{T} 1-\mathrm{T} 12\left(^{\circ}\right)$ & $-5[-10 ; 4]$ \\
$\mathrm{T} 4-\mathrm{T} 12\left(^{\circ}\right)$ & $52[44 ; 59]$ \\
$\mathrm{L} 1-\mathrm{S} 1\left(^{\circ}\right)$ & $40[32 ; 45]$ \\
\end{tabular}

BMI, body mass index; VC, vital capacity, IC, inspiratory capacity; ERV, expiratory reserve volume; FRC, functional residual capacity; $R V$, residual volume; TLC, total lung capacity; ODHA, odontoid-hip axis angle; SVA, sagittal vertical axis; C3-C7, cervical curvature between the third and seventh cervical vertebrae; T1-T12 and T4-T12, thoracic curvature between the first and twelfth and fourth and twelfth thoracic vertebrae, respectively; L1-S1, Lumbar curvature between the first lumbar vertebra and the sacrum.
TLC and RV, respectively, $\mathrm{IC}_{\mathrm{bpxr}}$ and $\mathrm{ERV}_{\mathrm{bpxr}}$ were compared to $\mathrm{IC}_{\mathrm{pft}}$ and $\mathrm{ERV}_{\mathrm{pft}}$ using Wilcoxon's signed rank test for paired data. BPXR data obtained at Vmax and Vmin were separately compared to BPXR data at Vrelax by Wilcoxon's signed rank test for paired data (no Vmin-Vmax comparisons). SVA was compared to $\mathrm{SVA}_{\text {simu }}$ and $\mathrm{ODHA}_{\text {sagittal }}$ was compared to $\mathrm{ODHA}_{\text {sagittSlsimu }}$ separately at Vmax and Vmin by Wilcoxon's signed rank test for paired data. Associations between 1 age and BPXR parameters at the three volumes studied,

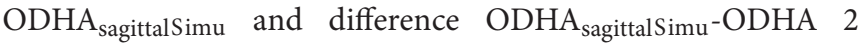
dynamic lung volumes and T1-T12 curvature, were evaluated using Spearman's correlation coefficient $r_{S}$. All tests were twotailed and $p$-values $<5 \%$ were considered statistically significant, except for the correlations with age which were adjusted with Benjamini-Hochberg's correction for multiple testing with a target False Discovery Rate of 5\%.

\section{RESULTS}

The complete protocol could be performed in the 50 subjects, but two subjects could not be analyzed due to BXPR acquisition issues. The following results therefore pertain to 48 subjects [22 women, age $34(26 ; 48)$ years, Body Mass Index $\left.23.6(21.8 ; 25.9) \mathrm{kg} / \mathrm{m}^{2}\right]$.

\section{BXPR Variables at Vrelax}

The baseline characteristics of the subjects and all BPXR variables at Vrelax are presented in Table 1. Of note, at Vrelax, the median thoracic kyphosis T1-T12 was $52^{\circ}(44 ; 59)$ and the median ODHA was $3^{\circ}(2 ; 4)$. These values are within the range of previously published normal values (Amabile et al., 2016; Amabile et al., 2018).

\section{Lung Volumes}

Lung volumes from reference pulmonary function tests were available in the 48 subjects constituting the analysis population (Table 1). Spirometric data could only be obtained in 44 of these subjects during BPXR acquisitions (technical issues in 4 subjects). The difference between $\mathrm{IC}_{\mathrm{pft}}$ and $\mathrm{IC}_{\mathrm{bpxr}}$ was $0.40(0.28 ; 0.74)$ $\mathrm{L}(p<0.01)$. The difference between $\mathrm{ERV}_{\mathrm{pft}}$ and $\mathrm{ERV}_{\mathrm{bxpr}}$ was $0.24(0.05 ; 0.45) \mathrm{L}(p<0.01)$. As a result, $\operatorname{Vmax}[6.1(5.3 ; 7.1)$ L] represented $94 \%(89 ; 96)$ of TLC and Vmin $[1.8(1.4 ; 2.2) \mathrm{L}]$ represented $113 \%(103 ; 127)$ of $\mathrm{RV}$.

\section{Effects of Vital Capacity on Postural Alignment}

The detailed BPXR results are provided in Figure 2 and Table 2 (examples of 3D reconstructions in one subject), Figures 3, 4. Going from Vrelax to Vmax reduced thoracic kyphosis (median T1-T12 from $52^{\circ}$ to $47^{\circ} ; p=0.0007$ ), reduced cervical lordosis (median $\mathrm{C} 3-\mathrm{C} 7$ from $-5^{\circ}$ to $4^{\circ} ; p=0.006$ ) and induced pelvic retroversion (median pelvic tilt from $12^{\circ}$ to $14^{\circ} ; p=0.002$ ). Conversely, going from Vrelax to Vmin accentuated thoracic kyphosis (median T1-T12 from $52^{\circ}$ to $63^{\circ} ; p=8.96 \times 10^{-12}$ ) and accentuated cervical lordosis (median $\mathrm{C} 3-\mathrm{C} 7$ from $-5^{\circ}$ to $-12^{\circ} ; p=6.70 \times 10^{-7}$ ). It also induced pelvic retroversion 


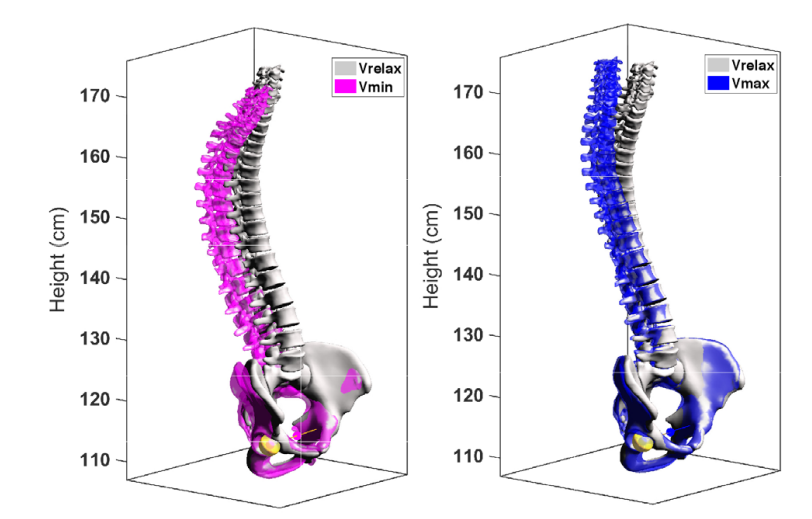

FIGURE 2 | Specific 3D models of one subject at Vrelax Vmax and Vmin. Left: Vrelax (gray) and Vmin (purple) are superimposed. Right: Vrelax (gray) and Vmax (blue) are superimposed.

(median pelvic tilt from $12^{\circ}$ to $17^{\circ} ; p=2.12 \times 10^{-9}$ ). In both cases (Vrelax to Vmax and Vrelax to Vmin) the $\mathrm{ODHA}_{3 D}$ angle was almost invariant (median variation of $1^{\circ}$ ).

\section{Simulated Absence of Pelvic and Cervical Compensation (Figures 4, 5)}

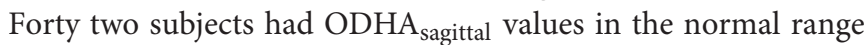
defined, previously in healthy subjects (Amabile et al., 2016, 2018) at Vrelax, 37 subjects at Vmin and 37 subjects at Vmax.

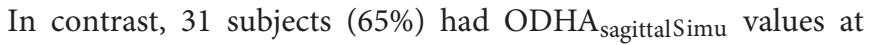
$\mathrm{Vmax}$ and/or Vmin outside of the normal range. The differences between ODHA sagittalSimu $_{\text {and ODHA }}$ sagittal were $2(0 ; 4)$ at Vmax $(p=0.001)$ and $4(0 ; 7)$ at $\operatorname{Vmin}(p<0.00001)$. Regarding SVA, the differences between $\mathrm{SVA}_{\text {simu }}$ and SVA were $7(-6 ; 21)$ at Vmax $(p<0.0001)$ and $37(7 ; 60)$ at $\operatorname{Vmin}(p<0.0001)$.

\section{Correlations Between Lung Volumes, BPXR Values and Age}

$\mathrm{ERV}_{\mathrm{bpxr}}$ correlated with the T1-T12 angle at $\mathrm{Vmin}\left(\mathrm{r}_{\mathrm{S}}=0.3329\right.$; $p=0.027)$. Similarly, IC $b_{p x r}$ was correlated with the T1-T12 angle at $\mathrm{V} \max \left(\mathrm{r}_{\mathrm{S}}=0.3204 ; p=0.034\right)$. In contrast, no correlation was observed between Vrelax and the T1-T12 angle at Vrelax $(p=0.154)$.

Age was correlated with more marked pelvic tilt at Vrelax, Vmax and Vmin, a more marked C3-C7 lordosis at Vrelax and Vmax (see Table 3). In contrast, no correlation was observed between age and T1-T12, L1-S1 and ODHA at any of the three lung volumes studied and between age and $\mathrm{ODHA}_{\text {sagittalsimu }}$ at Vmax and Vmin. Age was correlated with lower ERV $\mathrm{bpxr}_{\text {and }}$ greater $\mathrm{ERV}_{\mathrm{pft}}-\mathrm{ERV}_{\mathrm{bpxr}}$ difference (Figure 6). In contrast there was no correlation between age and neither $\mathrm{ERV}_{\mathrm{pft}}$ nor IC (be it $\mathrm{IC}_{\mathrm{pft}}, \mathrm{IC}_{\mathrm{bpxr}}$ or the difference between these values).

\section{DISCUSSION}

This study shows that the changes in thoracic spinal curvature induced by maximal inspiration and maximal expiration in healthy humans, are fully compensated in terms of the head-topelvis alignment. This compensation is achieved through changes in the cervical spinal curvature and changes in the pelvic tilt. Simulations strongly suggest that in the absence of these cervical and pelvic compensations verticality could be compromised to the point of being responsible for falls.

\section{Methodological Strengths and Limitations}

Respiratory-related changes in spinal curvature have been previously described (Dally, 1908), but this study is the first to describe postural adaptations over the range of vital capacity. It is also the first study to take advantage of the BPXR technology to address this issue. We obtained individual 3D skeleton models (Mitton et al., 2006; Dubousset et al., 2008; Humbert et al., 2009) at different lung volumes: this approach is known to allow a precise evaluation of postural alignment in weight bearing condition (Vialle et al., 2005; Amabile et al., 2016; Hasegawa et al., 2017). It has been validated in healthy subjects (Vialle et al., 2005; Amabile et al., 2016; Hasegawa et al., 2017) for the study of

TABLE 2 | BPXR variables at $V \max$ and $V$ min and their variations from Vrelax.

\begin{tabular}{|c|c|c|c|c|c|c|}
\hline & Vmax & Difference & $p$ & Vmin & Difference & $p$ \\
\hline Pelvic tilt $\left({ }^{\circ}\right)$ & $14[9 ; 18]$ & $1[0 ; 3]$ & 0.002 & $17[11 ; 23]$ & $5[1 ; 8]$ & $2 \times 10^{-9}$ \\
\hline Sacral slope $\left(^{\circ}\right)$ & $-40[-46 ;-34]$ & $1[-2 ; 4]$ & 0.166 & $-36[-43 ;-28]$ & $6[0 ; 9]$ & $6 \times 10^{-7}$ \\
\hline $\mathrm{ODHA}_{3 D}\left(^{\circ}\right)$ & $4[3 ; 6]$ & $1[0 ; 2]$ & $1.18 \times 10^{-5}$ & $4[2 ; 6]$ & $1[0 ; 2]$ & 0.014 \\
\hline ODHA $A_{\text {sagittal }}\left({ }^{\circ}\right)$ & $-4[-5 ;-2]$ & $-1[-2 ; 0]$ & $4.26 \times 10^{-6}$ & $-3[-5 ;-1]$ & $0[-1 ; 1]$ & 0.418 \\
\hline $\mathrm{ODHA}$ frontal $\left({ }^{\circ}\right)$ & $0[-1 ; 1]$ & $0[0 ; 1]$ & 0.002 & $0[-1 ; 1]$ & $0[0 ; 1]$ & 0.006 \\
\hline $\mathrm{SVA}(\mathrm{mm})$ & $-22[-34 ;-10]$ & $-11[-23 ;-5]$ & $9.49 \times 10^{-7}$ & $-6[-23 ; 9]$ & $3[-12 ; 21]$ & 0.239 \\
\hline $\mathrm{C} 3-\mathrm{C} 7\left(^{\circ}\right)$ & $4[-3 ; 8]$ & $4[-2 ; 11]$ & 0.006 & $-12[-17 ;-6]$ & $-7[-18 ;-1]$ & $6 \times 10^{-7}$ \\
\hline $\mathrm{T} 1-\mathrm{T} 12\left(^{\circ}\right)$ & $47[37 ; 56]$ & $-4[-9 ; 1]$ & 0.0007 & $63[55 ; 68]$ & $10[5 ; 12]$ & $8 \times 10^{-12}$ \\
\hline T4-T12 $\left(^{\circ}\right)$ & $33[25 ; 40]$ & $-5[-9 ; 0]$ & $1.18 \times 10^{-5}$ & $47[40 ; 53]$ & $6[2 ; 12]$ & $1 \times 10^{-8}$ \\
\hline L1-S1 $\left(^{\circ}\right)$ & $-56[-68 ;-51]$ & $0[-4 ; 5]$ & 0.512 & $-57[-66 ;-45]$ & $3[-1 ; 8]$ & 0.012 \\
\hline
\end{tabular}

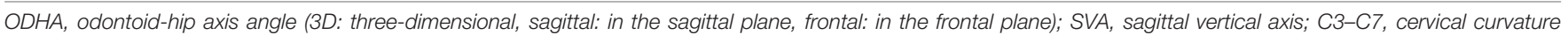

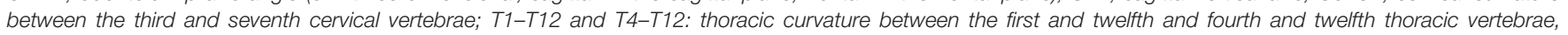
respectively; L1-S1, lumbar curvature between the first lumbar vertebra and the sacrum. 

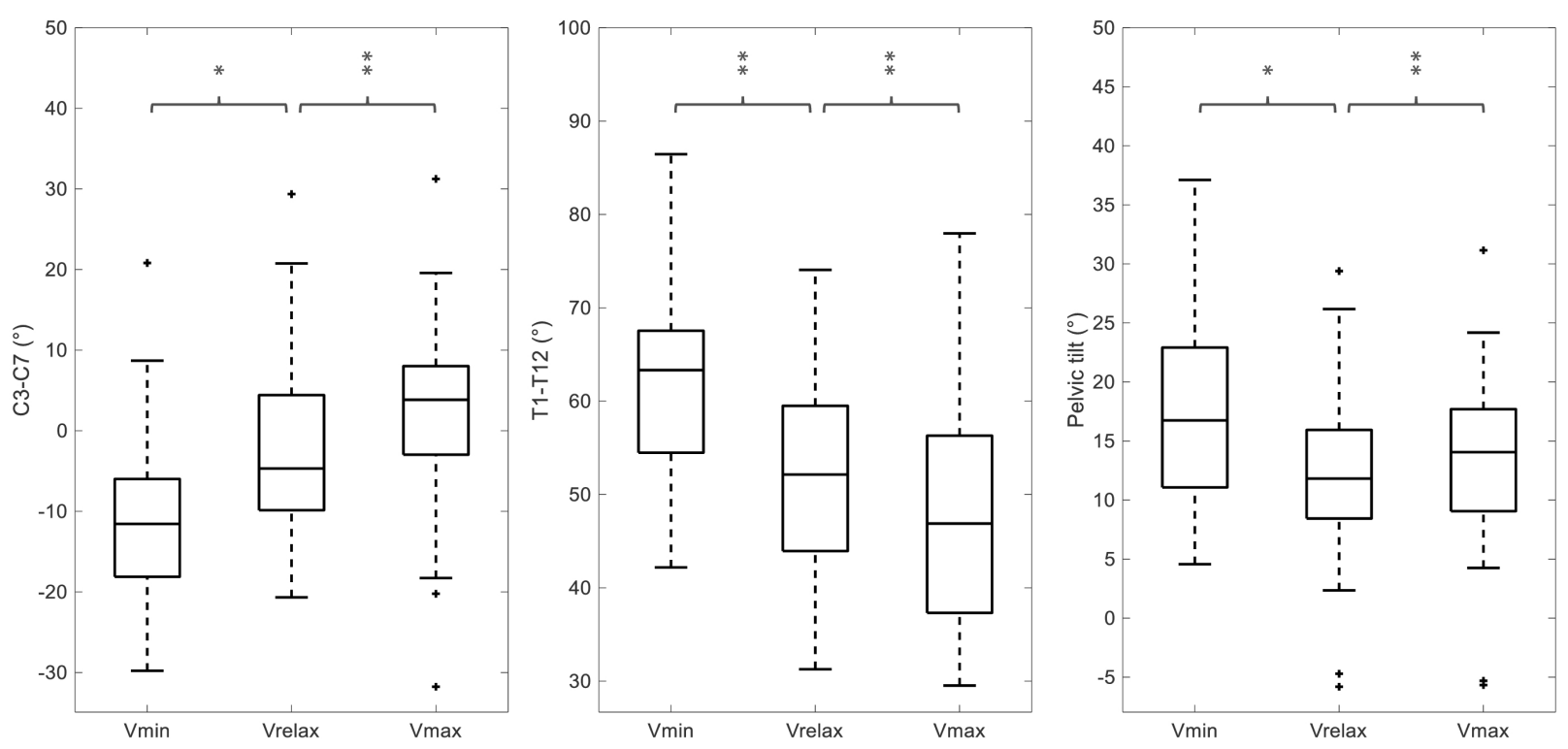

FIGURE 3 | Influence of lung volume on BPXR parameters. C3-C7, T1-T12 and pelvic tilt values at Vrelax, Vmax, and Vmin in the 48 subjects. ${ }^{*} p<0.01$ and $* * p<0.001$.
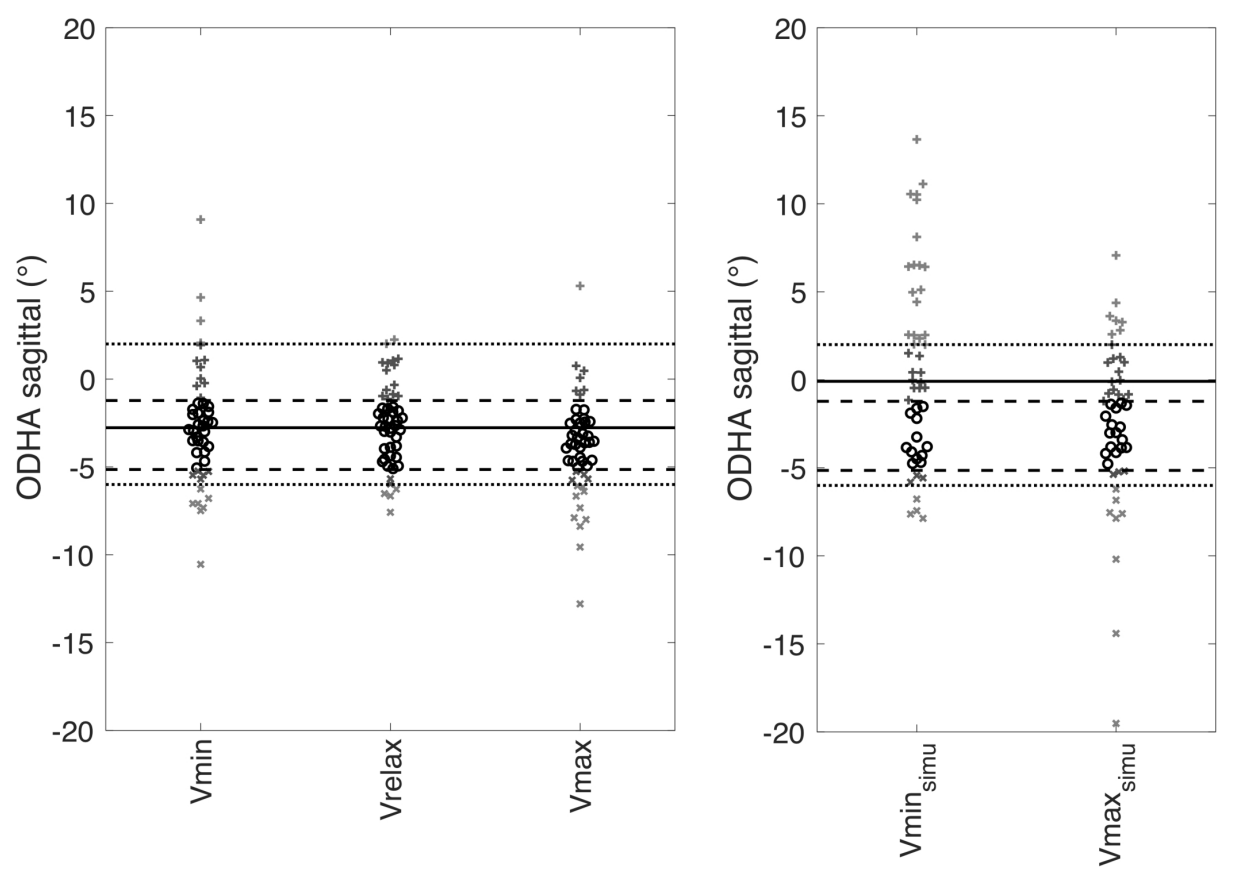

FIGURE 4 | ODHA values at the three lung volumes and ODHA simulated values in the absence of pelvic and cervical compensation at Vmax and Vmin. On the left,

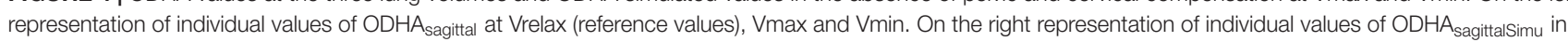
the absence of pelvic and cervical compensation at $V \max \left(V_{\max }\right.$ simu) and Vmin $\left(V_{m i n}\right.$ simu $)$. For both graphs, median of the reference values at Vrelax (in black solid line), 25-75th percentiles interval (in black dashed line) and normal values (Amabile et al., 2018) (in gray) are represented.

compensatory mechanisms during aging (Amabile et al., 2018), and in scoliotic patients (Ilharreborde et al., 2013).

We paid particular attention to perform BPXR acquisitions at reproducible lung volumes, hence the need to perform spirometric measurements during the procedure. The subjects therefore had to breathe into a spirometer and hold it themselves. Breathing through a spirometer has been shown to induce a postural constraint (Clavel et al., 2017). To limit the impact of this bias on our observations, we carefully instructed the subjects to hold the spirometer between the palms of their hands with 

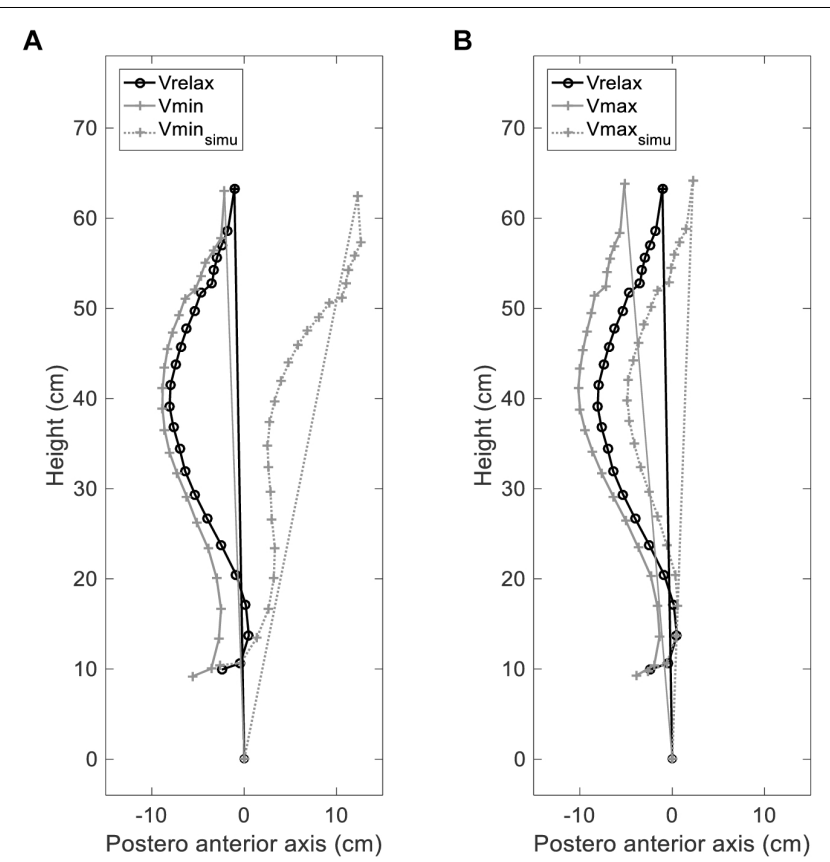

FIGURE 5 | Simulated effects of lung volume changes on verticality. ODHA: angle between the vertical plane and the line through odontoid (OD) and the midpoint of the line connecting the center of the two femoral heads $(\mathrm{HA})$; Vrelax: relaxation lung volume; Vmin: minimal lung volume; Vmax: maximal

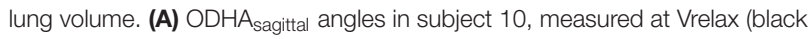
solid line) $\left(-1^{\circ}\right)$ and $V$ min (gray solid line) $\left(-5^{\circ}\right)$, and uncompensated (in the absence of pelvic and cervical compensation) simulated ODHA at Vmin $\left(V_{m i n}\right.$ simu gray dashed line) $\left(+11^{\circ}\right)$. (B) ODHA angles in the same subject, measured at Vrelax (black solid line) $\left(-1^{\circ}\right)$ and $V \max$ (gray solid line) $\left(-5^{\circ}\right)$, and uncompensated (in the absence of pelvic and cervical compensation) simulated ODHA at $V \max \left(\mathrm{Vmax}_{\text {simu }}\right.$ gray dashed line $)\left(+2^{\circ}\right)$.

TABLE 3 | Correlations between age and BPXR parameters.

\begin{tabular}{llll}
\hline & \multicolumn{1}{c}{$\boldsymbol{r}_{\mathbf{S}}$} & \multicolumn{1}{c}{$\boldsymbol{p}$} & \multicolumn{1}{c}{$\boldsymbol{q}$} \\
\hline Pelvic tilt at Vrelax & & & \\
Pelvic tilt atVmax & 0.3748 & 0.00867366 & 0.03324904 \\
Pelvic tilt at Vmin & 0.3949 & 0.00098087 & 0.01128 \\
C3-C7 at Vrelax & -0.3578 & 0.00547981 & 0.03055895 \\
C3-C7 at Vmax & -0.3866 & 0.01252155 & 0.04114223 \\
\hline
\end{tabular}

BPXR, biplanar X-ray; C3-C7, cervical curvature between the third and seventh cervical vertebrae; Vrelax, lung volume which corresponds to the functional residual capacity during BPXR acquisition; Vmax, lung volume after maximal inspiration during BPXR acquisition; Vmin, lung volume after maximal expiration during BPXR acquisition; $r_{s}$, Spearman's correlation coefficient; $p$ : associated $p$-value; $q$ : $p$-value adjusted with Benjamini-Hochberg's correction for multiple testing.

their shoulders relaxed, in a position that was very close to the reference position (namely at relaxed end-expiratory lung volume, without the spirometer). We can however not rule out that the spirometric measurements interfered with our subjects' standing posture. The amplitude of the corresponding changes, if any, was probably small respective to the postural modifications observed in response to the very large volume variations that we studied. Of note, Vmax and Vmin as measured during the

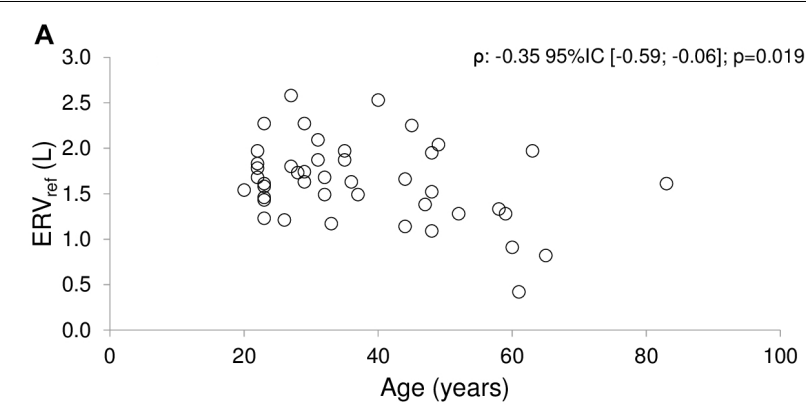

B
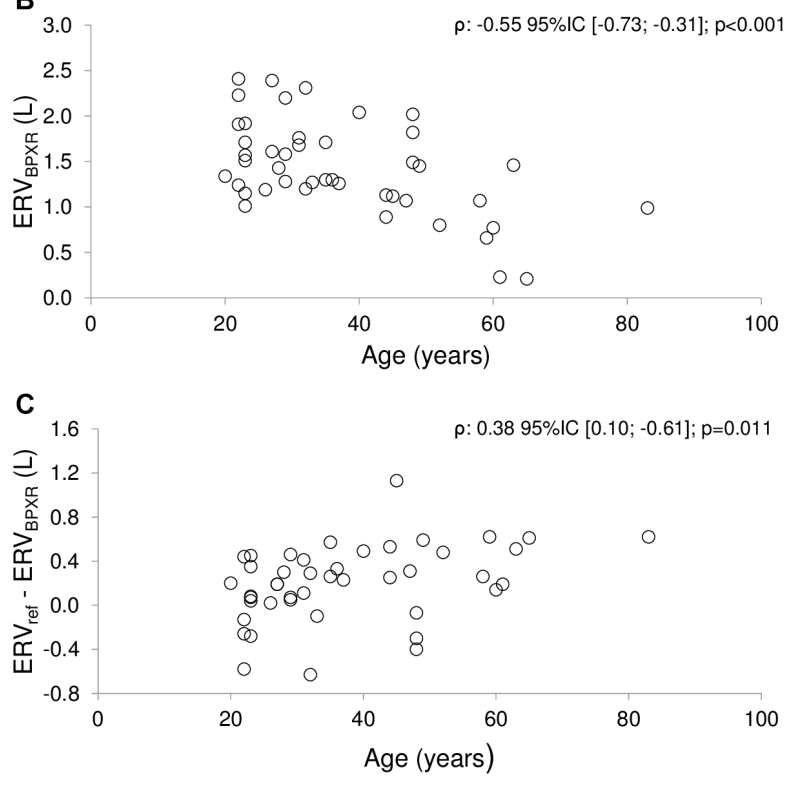

FIGURE 6 | Correlations between age and expiratory reserve volume. ERV, Expiratory Reserve Volume; BPXR, Biplanar Xrays. (A) Correlation between age and expiratory reserve volume measured prior to the BPXR acquisition (spirometric reference values $E R V_{\text {pft }}$ ). (B) Correlation between age and ERV measured during $B P X R$ acquisition ( $\left(E R V_{b p x r}\right)$. (C) Correlation between age and the difference $E R V_{p f t}-E R V_{\text {bpxr }}$. rs: Spearman's correlation coefficient; $p$ : associated $p$-value; q: $p$-value adjusted with Benjamini-Hochberg's correction for multiple testing.

BPXR acquisitions, significantly differed from TLC and RV. Nevertheless, the differences were small, and the dispersion of the values was limited.

As a limitation of the study, we acknowledge that our results pertain to postural adaptations to maximal lung volumes described under static rather than dynamic conditions. This limits their transposition to the study of respiratory-related postural perturbations and adaptations in real-life, particularly for hyperventilation, which is known to increase breathingrelated postural perturbation (Hodges et al., 2002; Hamaoui et al., 2010; David et al., 2012) while holding the breath (as it was required in our study) is known to reduce or cancel it (Caron et al., 2004). In addition, nasal breathing maneuvers were not tested in these experiments for physiological comparison, as subjects were instructed to breathe through a mouthpiece. However, evaluations were done in a static condition, and 
consequently the spinal alignment we observed at extreme lung volumes was related to lung volume variations and was not influenced by the route of breathing before holding the breath.

\section{Postural Alignment and Vital Capacity}

At extreme lung volumes, we observed variations of thoracic curvature resembling those long described during breathing (Dally, 1908) but of an expectedly greater amplitude. Indeed, inspiring to TLC and expiring to RV brought the T1-T12 angle outside its normal range (Vialle et al., 2005; Amabile et al., 2016) and resulted in highly variable SVA values. In the absence of compensation, this would compromise upright static balance (Roussouly et al., 2005; Vialle et al., 2005; Roussouly and Pinheiro-Franco, 2011b). Yet, in our subjects, verticality was preserved as ODHA values remained within the normal range (Amabile et al., 2016). We did observe compensations at the pelvic and lumbar level, as it is the case during resting breathing (Kantor et al., 2001; Caron et al., 2004; Hodges et al., 2007; Hamaoui et al., 2010; Talasz et al., 2011). We also observed the activation of a cervical compensatory mechanism (Figure 3 and Table 2). Combined pelvic and cervical compensations have been described during aging (Diebo et al., 2015; Amabile et al., 2018) and in degenerative diseases altering spinal posture (Roussouly and Pinheiro-Franco, 2011b; Diebo et al., 2015; Paternostre et al., 2017). They restore an adequate alignment of the head and pelvis to maintain horizontal gaze (Hasegawa et al., 2017) while achieving an energetically economical standing position (DuvalBeaupere et al., 1992). To our knowledge, cervical compensation has not been described before in the context of respiratory-related postural perturbations. This is possibly because the respiratoryinduced changes in thoracic curvature during tidal breathing are not sufficient to trigger cervical adaptations, but become so when lung volume changes are very important as during our experiment (Scheer et al., 2013). In our subjects, changes in cervical spinal curvature appeared as a predominant postural compensatory mechanism, while the lumbar compensation was limited. The lumbar curvature is mostly determined by pelvic incidence, defined as the angle perpendicular to the sacral plate at its midpoint, and a line connecting the same point to the center of the bicoxofemoral axis. This angle is constant whatever the position; its values for one subject determine the global spinal alignment and particularly the magnitude of the lumbar lordosis, which partly explains the relatively low mobility of this spine segment (Roussouly et al., 2005). Moreover, inspiratory and expiratory efforts over the full range of vital capacity both induce increase of lumbar spinal stiffness, which in addition may limit lumbar mobility at extreme lung volumes (Shirley et al., 2003). This improvement in lumbar stiffness is due to an increase of trunk muscle activity and intra-abdominal pressure, and by the direct action of the diaphragm on the lumbar spine via its insertions (Shirley et al., 2003). Consequently, dramatic changes of thoracic curvature when maximally mobilizing lung volume, predominantly trigger cervical and pelvic segments, which are freer of motion (Roussouly and Pinheiro-Franco, 2011a).

In line with this, changes in lumbar curvature were small in our subjects both at Vmax (where they did not reach statistical significance) and at Vmin.
Moreover, the cervical lordosis is highly correlated to thoracic hyphosis when spine alignment varies (Shirley et al., 2003). In our subjects, it was adjusted to maintain the horizontal gaze when mobilizing vital capacity.

Simulations showed that in the absence of compensation, $65 \%$ of our subjects would have had ODHA values outside the normal range at either of the lung volumes studied, and therefore a compromised balance. Figure 5 clearly illustrates this phenomenon in one subject. Of note, maximum expiration induced more marked changes in thoracic spinal curvature (hyperkyphosis) than maximum inspiration. It also induced more intense pelvic postural compensation (retroversion) than maximum inspiration, suggesting that cervical compensations was less efficient during expiration than inspiration (Scheer et al., 2013). As a result, maximal expiration appears theoretically more threatening to postural stability than maximal inspiration.

This study fuels the notion that alterations in postural compensatory mechanisms involved by respiratory-related postural perturbations could constitute one of the determinants of the postural dysfunction observed during chronic respiratory diseases known to induce changes in lung volume or chest geometry, such as chronic obstructive pulmonary disease (COPD) (Janssens et al., 2014; Lahousse et al., 2015).

\section{Effects of Age}

In our study population at Vrelax, age was significantly associated with more marked pelvic retroversion and more marked cervical lordosis. This is consistent with age-related postural adjustments previously reported (Diebo et al., 2015; Amabile et al., 2018). Of note, the postural adjustments that we observed during maximum expiration consist in an exaggeration of this pattern. Compensatory postural mechanisms during expiration could therefore be less effective in older people.

Normal aging is accompanied by decreased vital capacity with a decreased expiratory reserve volume -observed in our study population- and a decreased inspiratory capacity -not observed in our study population- (Turner et al., 1968). This is generally attributed to changes in thoracopulmonary mechanical properties (Verbeken et al., 1992; Galetke et al., 2007). The present data raise the hypothesis that the agerelated reduction in vital capacity could partly proceed from deteriorated compensation of the respiratory-related postural perturbation. This is supported by the correlations observed in our subjects between lung volumes and T1-T12 curvature (increased kyphosis during expiration; decreased kyphosis during inspiration): greater lung volumes induce greater perturbations of postural alignment hence a greater need of postural compensation to maintain balance. This is also supported by the smaller IC and ERV values during BPXR acquisitions compared to reference values: although technical issues are possible, the subjects could have "censored" their respiratory efforts during BPXR acquisitions to preserve their balance. Of note, the differences between BPXR lung volumes and reference lung volumes were more marked with age (namely in subjects with lower postural compensation capacity) and particularly so for maximal expiration (that threatens balance more than maximal inspiration, see above). This postulated mechanism 
(impact of limited postural compensation capabilities on vital capacity) could, beyond aging, be called on to explain part of the impact of thoracic deformities on lung volumes [e.g., scoliosis (Szopa and Domagalska-Szopa, 2017) or secondary spinal lesions (Kenis-Coskun et al., 2017)].

\section{CONCLUSION}

Extreme lung volume variations over vital capacity is associated with changes of thoracic curvature bringing it outside the normal range, which would theoretically compromise verticality. This is however fully compensated by adaptations of the cervical curvature and pelvic tilt to preserve adequate head-to-pelvis verticality and horizontal gaze alignment. Lung volume related postural perturbations increase with age, but age did not affect head-to-pelvis alignment. Future studies are needed to investigate potential postural dysfunction in chronic respiratory diseases that induce changes of lung volume or chest geometry, such as COPD.

\section{ETHICS STATEMENT}

All subjects gave written informed consent in accordance with the Declaration of Helsinki. The protocol was approved by the Comité de Protection des Personnes Ile-de-France VI Paris (Ethics Committee).

\section{REFERENCES}

Amabile, C., Le Huec, J. C., and Skalli, W. (2018). Invariance of head-pelvis alignment and compensatory mechanisms for asymptomatic adults older than 49 years. Eur. Spine J. 27, 458-466. doi: 10.1007/s00586-016-4830-8

Amabile, C., Pillet, H., Lafage, V., Barrey, C., Vital, J. M., and Skalli, W. (2016). A new quasi-invariant parameter characterizing the postural alignment of young asymptomatic adults. Eur. Spine J. 25, 3666-3674. doi: 10.1007/s00586-0164552-y

Brown, R., Leith, D. E., and Enright, P. L. (1998). Multiple breath helium dilution measurement of lung volumes in adults. Eur. Respir. J. 11, 246-255. doi: 10.1183/09031936.98.11010246

Caron, O., Fontanari, P., Cremieux, J., and Joulia, F. (2004). Effects of ventilation on body sway during human standing. Neurosci. Lett. 366, 6-9. doi: 10.1016/j. neulet.2004.04.085

Clavel, L., Attali, V., Jacq, O., Nierat, M. C., Similowski, T., Rouch, P., et al. (2017). Breathing through a spirometer perturbs balance. Comput. Methods Biomech. Biomed. Engin. 20, 41-42. doi: 10.1080/10255842.2017. 1382851

Dally, J. F. (1908). An inquiry into the physiological mechanism of respiration, with especial reference to the movements of the vertebral column and diaphragm. J. Anat. Physiol. 43, 93-114.

David, P., Laval, D., Terrien, J., and Petitjean, M. (2012). Postural control and ventilatory drive during voluntary hyperventilation and carbon dioxide rebreathing. Eur. J. Appl. Physiol. 112, 145-154. doi: 10.1007/s00421-0111954-8

Diebo, B. G., Ferrero, E., Lafage, R., Challier, V., Liabaud, B., Liu, S., et al. (2015). Recruitment of compensatory mechanisms in sagittal spinal malalignment is age and regional deformity dependent: a full-standing axis analysis of key radiographical parameters. Spine 40, 642-649. doi: 10.1097/BRS. 0000000000000844

Dubousset, J. (1994). “Three-dimensional analysis of the scoliotic deformity”, in Pediatric Spine: Principles and Practices, ed. S. L. Weinstein (New York, NY: Raven Press Ltd).

\section{AUTHOR CONTRIBUTIONS}

VA, LC, BS, and TS contributed substantially to the study design, data analysis and interpretation, and the writing of the manuscript. WS, PR, IR, and SR-N contributed substantially to the data analysis and interpretation and to the writing of the manuscript.

\section{FUNDING}

"Legs Poix" (LEG 1604) of the Chancellerie des Universités de Paris. VA is the recipient of a grant "poste d'accueil APHP/Arts et Métiers ParisTech," délégation à la Recherche Clinique et à l'Innovation (DRCI), Assistance Publique Hôpitaux de Paris (APHP). LC was supported by a Ph.D. fellowship from ENS Cachan. The authors acknowledge the support of the Paristech BiomeCAM chair on subject specific modeling, with the support of Société Générale and COVEA.

\section{ACKNOWLEDGMENTS}

The authors are grateful to Mr. Anthony Saul, professional medical translator and editor, for his help with English style and grammar, and to Mrs. Sonia Simoes for technical support.

Dubousset, J., Charpak, G., Skalli, W., de Guise, J., Kalifa, G., and Wicart, P. (2008). [Skeletal and spinal imaging with EOS system]. Arch. Pediatr. 15, 665-666.

Duval-Beaupere, G., Schmidt, C., and Cosson, P. (1992). A Barycentremetric study of the sagittal shape of spine and pelvis: the conditions required for an economic standing position. Ann. Biomed. Eng. 20, 451-462. doi: 10.1007/bf02368136

Galetke, W., Feier, C., Muth, T., Ruehle, K. H., Borsch-Galetke, E., and Randerath, W. (2007). Reference values for dynamic and static pulmonary compliance in men. Respir. Med. 101, 1783-1789. doi: 10.1016/j.rmed.2007.02.015

Granata, K. P., and Wilson, S. E. (2001). Trunk posture and spinal stability. Clin. Biomech. 16, 650-659. doi: 10.1016/s0268-0033(01)00064-x

Grimstone, S. K., and Hodges, P. W. (2003). Impaired postural compensation for respiration in people with recurrent low back pain. Exp. Brain Res. 151, 218-224. doi: 10.1007/s00221-003-1433-5

Hamaoui, A., Gonneau, E., and Le Bozec, S. (2010). Respiratory disturbance to posture varies according to the respiratory mode. Neurosci. Lett. 475, 141-144. doi: 10.1016/j.neulet.2010.03.064

Hasegawa, K., Okamoto, M., Hatsushikano, S., Shimoda, H., Ono, M., Homma, T., et al. (2017). Standing sagittal alignment of the whole axial skeleton with reference to the gravity line in humans. J. Anat. 230, 619-630. doi: 10.1111/joa. 12586

Hodges, P. W., Gurfinkel, V. S., Brumagne, S., Smith, T. C., and Cordo, P. C. (2002). Coexistence of stability and mobility in postural control: evidence from postural compensation for respiration. Exp. Brain Res. 144, 293-302. doi: 10.1007/s00221-002-1040-x

Hodges, P. W., Sapsford, R., and Pengel, L. H. (2007). Postural and respiratory functions of the pelvic floor muscles. Neurourol. Urodyn. 26, 362-371. doi: 10.1002/nau.20232

Humbert, L., De Guise, J. A., Aubert, B., Godbout, B., and Skalli, W. (2009). $3 \mathrm{D}$ reconstruction of the spine from biplanar X-rays using parametric models based on transversal and longitudinal inferences. Med. Eng. Phys. 31, 681-687. doi: 10.1016/j.medengphy.2009.01.003

Ignasiak, D., Ferguson, S. J., and Arjmand, N. (2016). A rigid thorax assumption affects model loading predictions at the upper but not lower lumbar levels. J. Biomech. 49, 3074-3078. doi: 10.1016/j.jbiomech.2016.07.006 
Ilharreborde, B., Sebag, G., Skalli, W., and Mazda, K. (2013). Adolescent idiopathic scoliosis treated with posteromedial translation: radiologic evaluation with a $3 \mathrm{D}$ low-dose system. Eur. Spine J. 22, 2382-2391. doi: 10.1007/s00586-013-2776-7

Janssens, L., Brumagne, S., McConnell, A. K., Claeys, K., Pijnenburg, M., Goossens, N., et al. (2014). Impaired postural control reduces sit-to-stand-to-sit performance in individuals with chronic obstructive pulmonary disease. PLoS One 9:e88247. doi: 10.1371/journal.pone.0088247

Kantor, E., Poupard, L., Le Bozec, S., and Bouisset, S. (2001). Does body stability depend on postural chain mobility or stability area? Neurosci. Lett. 308, 128-132. doi: 10.1016/s0304-3940(01)01986-3

Kenis-Coskun, O., Karadag-Saygi, E., Bahar-Ozdemir, Y., Gokdemir, Y., Karadag, B., and Kayhan, O. (2017). The involvement of musculoskeletal system and its influence on postural stability in children and young adults with cystic fibrosis. Ital J. Pediatr. 43:106. doi: 10.1186/s13052-017-0426-0

Lahousse, L., Verlinden, V. J., van der Geest, J. N., Joos, G. F., Hofman, A., Stricker, B. H., et al. (2015). Gait patterns in COPD: the Rotterdam study. Eur. Respir. J. 46, 88-95. doi: 10.1183/09031936.00213214

Liebsch, C., Graf, N., Appelt, K., and Wilke, H. J. (2017). The rib cage stabilizes the human thoracic spine: an in vitro study using stepwise reduction of rib cage structures. PLoS One 12:e178733. doi: 10.1371/journal.pone.0178733

Mitton, D., Deschenes, S., Laporte, S., Godbout, B., Bertrand, S., de Guise, J. A., et al. (2006). 3D reconstruction of the pelvis from bi-planar radiography. Comput. Methods Biomech. Biomed. Engin. 9, 1-5. doi: 10.1080/ 10255840500521786

Paternostre, F., Charles, Y. P., Sauleau, E. A., and Steib, J. P. (2017). Cervical sagittal alignment in adult hyperkyphosis treated by posterior instrumentation and in situ bending. Orthop. Traumatol. Surg Res. 103, 53-59. doi: 10.1016/j.otsr. 2016.10.003

Perennou, D. A., Mazibrada, G., Chauvineau, V., Greenwood, R., Rothwell, J., Gresty, M. A., et al. (2008). Lateropulsion, pushing and verticality perception in hemisphere stroke: a causal relationship? Brain 131, 2401-2413. doi: 10.1093/ brain/awn 170

Roussouly, P., Gollogly, S., Berthonnaud, E., and Dimnet, J. (2005). Classification of the normal variation in the sagittal alignment of the human lumbar spine and pelvis in the standing position. Spine 30, 346-353. doi: 10.1097/01.brs. 0000152379.54463 .65

Roussouly, P., and Pinheiro-Franco, J. L. (2011a). Biomechanical analysis of the spino-pelvic organization and adaptation in pathology. Eur. Spine J. 20(Suppl. 5), 609-618. doi: 10.1007/s00586-011-1928-x

Roussouly, P., and Pinheiro-Franco, J. L. (2011b). Sagittal parameters of the spine: biomechanical approach. Eur. Spine J. 20(Suppl. 5), 578-585. doi: 10.1007/ s00586-011-1924-1
Scheer, J. K., Tang, J. A., Smith, J. S., Acosta, F. L., Protopsaltis, T. S., Blondel, B., et al. (2013). Cervical spine alignment, sagittal deformity, and clinical implications: a review. J. Neurosurg. Spine 19, 141-159. doi: 10.3171/2013.4. SPINE12838

Shirley, D., Hodges, P. W., Eriksson, A. E., and Gandevia, S. C. (2003). Spinal stiffness changes throughout the respiratory cycle. J. Appl. Physiol. 95, 1467-1475. doi: 10.1152/japplphysiol.00939.2002

Szopa, A., and Domagalska-Szopa, M. (2017). Correlation between respiratory function and spine and thorax deformity in children with mild scoliosis. Medicine 96:e7032. doi: 10.1097/md.0000000000007032

Talasz, H., Kremser, C., Kofler, M., Kalchschmid, E., Lechleitner, M., and Rudisch, A. (2011). Phase-locked parallel movement of diaphragm and pelvic floor during breathing and coughing-a dynamic MRI investigation in healthy females. Int. Urogynecol. J. 22, 61-68. doi: 10.1007/s00192-010-1240-z

Turner, J. M., Mead, J., and Wohl, M. E. (1968). Elasticity of human lungs in relation to age. J. Appl. Physiol. 25, 664-671. doi: 10.1152/jappl.1968.25.6.664

Verbeken, E. K., Cauberghs, M., Mertens, I., Clement, J., Lauweryns, J. M., and Van de Woestijne, K. P. (1992). The senile lung. Comparison with normal and emphysematous lungs. 2. Functional aspects. Chest 101, 800-809.

Vialle, R., Levassor, N., Rillardon, L., Templier, A., Skalli, W., and Guigui, P. (2005). Radiographic analysis of the sagittal alignment and balance of the spine in asymptomatic subjects. J. Bone Joint Surg. Am. 87, 260-267. doi: 10.2106/jbjs. d.02043

Vital, J. M., and Senegas, J. (1986). Anatomical bases of the study of the constraints to which the cervical spine is subject in the sagittal plane. A study of the center of gravity of the head. Surg. Radiol. Anat. 8, 169-173. doi: 10.1007/ bf02427845

Wanger, J., Clausen, J. L., Coates, A., Pedersen, O. F., Brusasco, V., Burgos, F., et al. (2005). Standardisation of the measurement of lung volumes. Eur. Respir. J. 26, 511-522.

Conflict of Interest Statement: The authors declare that the research was conducted in the absence of any commercial or financial relationships that could be construed as a potential conflict of interest.

Copyright (C) 2019 Attali, Clavel, Rouch, Rivals, Rémy-Néris, Skalli, Sandoz and Similowski. This is an open-access article distributed under the terms of the Creative Commons Attribution License (CC BY). The use, distribution or reproduction in other forums is permitted, provided the original author(s) and the copyright owner(s) are credited and that the original publication in this journal is cited, in accordance with accepted academic practice. No use, distribution or reproduction is permitted which does not comply with these terms. 